\title{
Migrar y ser migrante: nociones de migrantes extranjeros actuales asentados en cuatro ciudades del sur de Chile
}

\author{
Andrea Corvalán Nazal \\ Investigadora independiente \\ andrea.corvalan.nazal@gmail.com \\ Carlos Reyes Velásquez \\ Universidad de La Frontera \\ reyesvelasquezc@gmail.com \\ Nelson Vergara Muñoz \\ Universidad de Los Lagos \\ nvergara@ulagos.cl
}

Recepción: 30-06-2016

Aceptación: 05-05-2018

Publicación: 16-10-2018

\section{Resumen}

El artículo presenta resultados de un estudio cualitativo que exploró las nociones sobre migrar y ser migrante que extranjeros asentados en cuatro ciudades del sur de Chile (Valdivia, Osorno, Puerto Montt y Castro) tienen sobre su propio proceso migratorio. Con el propósito de construir teoría sustantiva derivada de los datos, metodológicamente se desarrolló a partir de las orientaciones procedimentales de la Teoría Fundamentada (Glaser y Strauss, 1967; Strauss y Corbin, 2002; Salinas, 2009; Flores y Naranjo, 2013), y se aplicaron entrevistas semiestructuradas a 21 actores de procedencia europea, latinoamericana, caribeña, asiática y de Oriente Medio. Como principales resultados emergieron: por un lado, concepciones sobre migrar asociadas a procesos de identificación cultural relacionados con la obliteración voluntaria o involuntaria de las prácticas relacionales de origen en el lugar de asentamiento, y también su reproducción como resistencia para no perderlas; y por otro, concepciones sobre ser migrante construidas en base a lo que los participantes creen que los chilenos piensan sobre ellos, relevando valoraciones positivas para los europeos y negativas para los latinoamericanos, jerarquizadas en torno a la apariencia física, el color de piel y prejuicios sobre oficios y/o desempeños laborales esperados. Paralelamente, se releva la autoidentificación no migrante y migrante como persona común y corriente, como afán por subvertir clasificaciones dominantes que reproducirían relaciones de desigualdad económica y exclusión cultural. Por último, se concluye que la migración ante todo es, para los propios migrantes, un proceso de crecimiento y enriquecimiento personal independiente de los motivos de salida y las condiciones materiales o afectivas vividas en el lugar de asentamiento.

Palabras clave: migración internacional en el sur de Chile; subjetividad de los migrantes; sociología experiencial; sociología de las migraciones; teoría fundamentada 
Abstract. Migrating and being a migrant: Notions of current foreign migrants settled in four cities of southern Chile

This article presents the results of a qualitative study which explored the notions of migrating and being a migrant that foreigners settled in four cities of southern Chile (Valdivia, Osorno, Puerto Montt and Castro) have regarding their own migration process. In order to construct a substantive theory derived from the data, the methodology was developed based on the procedural guidelines of Grounded Theory (Strauss and Corbin, 2002) using semi-structured of 21 participants from Europe, Latin American, the Caribbean, Asia and the Middle East. The main results reveal that migration concepts associated with cultural identification processes are related to the voluntary or involuntary obliteration of relational practices of origin in the place of settlement and reproduction as a form of resistance to not lose such practices. Moreover, conceptions of being a migrant built on what participants believe that Chileans think about them reveal that Europeans are valued positively and Latin Americans are valued negatively, nested around physical appearance, skin color and prejudices about trades and/or expected work performance. Likewise, non-migrants and migrants identify themselves as ordinary people in a desire to subvert the dominant classifications that reproduce relations of economic inequality and cultural exclusion. Finally, we conclude that, for the migrants themselves, migration is primarily a process of growth and personal enrichment regardless of the reasons for departure and the material or emotional conditions experienced in the place of settlement.

Keywords: international migration; southern Chile; subjectivity of migrants; experiential sociology; sociology of migrations; grounded theory

\section{Sumario}

1. Introducción

4. Discusión

2. Metodología

Referencias bibliográficas

3. Resultados

\section{Introducción}

En el ámbito de las ciencias sociales, el estudio de las migraciones internacionales hoy tiene un lugar de primacía para la construcción de objetos en dominios disciplinares tan diversos como los de la sociología, la geografía, las relaciones internacionales, la antropología, el derecho, la ciencia política o la comunicación, cuyo aval lo encontramos en la producción literaria de investigadores y pensadores institucionalizados globalmente por la academia occidental (Appadurai, 2001; Arizpe, 1978; Augé, 2007; Benhabib, 2009; Borjas, 2013; Brettel y Hollifield, 2000; Castles, 2010; De Sousa Santos, 1998; Grosfoguel, 2007; Hatton y Williamson, 2004; Harvey, 2003; Sassen, 2013, 2007 y 2003) y en la de otros autores con aportes muy importantes pero de alcance divulgativo más anclado al ámbito iberoamericano (Benítez, 2013; Martínez y Orrego, 2016; Pedone, 2010; Pedreño, 2005; Souto Galván, 2013; Tezanos, 2007; Wagman, 2006). Sin embargo, la creciente popularidad temática de 
lo migratorio también trae consigo un aspecto contradictorio desalentador para la comprensión acabada del fenómeno, pues si por un lado amplifica la diversidad de problemas que lo articulan en torno a dimensiones económicodemográficas, políticas, culturales e histórico-sociales, por otro lado disminuye la producción de ese conocimiento con relevo de la subjetividad de quienes migran. En esta línea, nos sumamos a la crítica que García y Verdú (2008) hacen al determinismo económico/economicista que asistiría al estudio académico de las migraciones internacionales, y también explicitamos nuestra deriva con el panorama investigativo que en Chile construye sus problemas desde las siguientes aproximaciones: a) una sociocultural que investiga un plano más o menos idealizado que preconcibe colectivos específicos como agentes subalternos portadores del cambio social (Poo, 2008); b) la del discurso público de los medios de comunicación y el estudio de las representaciones discursivas con las que tales dispositivos criminalizarían la migración fronteriza (Poo, 2009; Doña, 2002; Gascón, 2010); c) los estudios basados en datos estadísticos que sobre las dimensiones trabajo/cesantía o consumo de bienes y servicios reproducen información sobre ecuatorianos, peruanos o bolivianos pobres asentados en la capital o en territorios del norte del país.

A propósito de estas orientaciones generales de campo, Cano y Soffia (2009) señalan que, aun cuando la agenda de investigación en Chile es modesta, por un lado permite identificar un abultado corpus literario con indagaciones limítrofes, caracterizado por un enfoque sociodemográfico y el interés en problemáticas de integración ciudadana útiles para la configuración de un estado de la cuestión migratoria peruana y boliviana en el país (Mella y Stoherel, 1999; Jiménez y Huatay, 2005; Norambuena, 2004); y por otro lado, visibiliza una creciente exploración en la migración fronteriza femenina y la cosificación de mujeres asociada al trabajo precarizado y las relaciones de exclusión racista en las que devienen frente a las prestaciones de sanidad, bienestar y protección del Estado en general (Tijoux y Córdova, 2015; Tijoux, 2011 y 2007; Carrère y Carrère, 2015). Sin embargo, si de "estado del arte» se ha de hablar, autores como Lube y Garcés (2014) consideran que lo anterior es discutible, pues sería resultado de una construcción metonímica que extrapola datos recogidos en casos específicos de la capital del país no representativos de la diversidad migratoria que acontece en otras ciudades de la región chilena. Esta crítica es clave, pues básicamente devela una desprolijidad epistemológica en que la generalidad del campo de estudios construye y comunica un tipo particular de conocimiento que distorsiona sus recortes espaciales, convirtiendo hallazgos localizados en totalizaciones arbitrarias sobre la «realidad» de las migraciones internacionales «en Chile». De modo complementario, los autores señalan que los estudios referidos a otras regiones del país aportan, mayoritariamente, datos censales que harían «intuir una ausencia de interés por parte de los investigadores [...] en realizar trabajo de campo presencial y cualitativo en estas regiones otras del norte o sur chilenos» (Lube y Garcés, 2014: 230). No obstante, convendría mencionar algunos trabajos sobre migrantes por amenidad o estilo de vida realizados en el área de montaña y lagos de la Norpatagonia 
chilena, que indagan procesos de movilidad contemporánea desprovistos de motivaciones económicas en búsqueda de lo que se entiende como «mejor calidad de vida» (Zunino y Hidalgo, 2010; Zunino et al., 2016); como también la aproximación a motivaciones y expectativas migratorias de mujeres de frontera en la Región de Tarapacá y las «redes de apoyo» emocional e informativo que ellas tejen en la ciudad de Iquique, al norte del país (Tapia y Ramos, 2013).

En esta línea, aunque situado sobre un enclave de migrantes en el sector de la Plaza de Armas de Santiago, no se puede dejar de mencionar la construcción de objetos en torno a la «maternidad transnacional» que Stefoni (2013) desarrolla desde un enfoque etnográfico con las prácticas cotidianas de mujeres y su relación a distancia con hijos e hijas a través del uso de locutorios; el caso de migrantes «esquineros» en que la misma investigadora (Stefoni, 2015) indaga el habitar de un espacio específico como prácticas masculinas que organizaría procesos de diferenciación, entre sí y entre el «nosotros» migrante y la comunidad local, junto con la reproducción del orden de género que relegaría a las mujeres al ámbito doméstico; o la cartografía social en la que Ducci y Rojas (2010) relevan la resignificación de lugares que migrantes peruanos irían dinamizando mediante la proyección de sus expresiones culturales y sus prácticas de trabajo y ocio colaborativo en el espacio público que han convenido denominar «la nueva Lima».

En cualquier caso, la revisión de literatura revela que las aproximaciones cualitativas a la migración internacional en Chile desarrollan sus problemas sobre dos planos preponderantes: a) colectivos específicos con características económicas de origen, motivos de migración, lugar de asentamiento y circunstancias culturales vividas en él igualmente específicas (como peruanos, bolivianos o ecuatorianos pobres que migran a Chile para trabajar, se establecen en Santiago y sufren discriminación y exclusión en general); b) orientación de género que, bajo el rótulo "feminización de las migraciones», construye el objeto desde una perspectiva sociocultural que estudia casos de mujeres de frontera asentadas en la capital del país desempeñando trabajos domésticos, de bajo prestigio social y económico, que «visibiliza lo racial y lo nacional como ejes que se suman a la clase y el género [...] encuadrando las relaciones sociales que se producen al interior de este trabajo» (Stefoni y Fernández, 2011: 46).

Frente a lo anterior, la investigación que aquí se presenta cobra relevancia puesto que propone una mirada comprensiva más amplia, que centra su aproximación en la experiencia del sujeto para pensar la migración, desde ahí, como un proceso complejo que, "como cualquier fenómeno social, es la suma de innumerables historias individuales, decisiones aleatorias, proyectos parcialmente conscientes, trayectorias existenciales» (Dal Lago, en Pinzani, 2010: 515). Destaca porque explora las migraciones internacionales en locaciones del sur del país no estudiadas por la academia nacional, y porque considera un perfil heterogéneo de «migrante» respecto a procedencia, género, motivos de migración y condiciones materiales o afectivas vividas en el lugar de asentamiento. En suma, este artículo entrega resultados sustantivos de una investigación que no tiene como propósito reproducir conocimiento académico ni prenociones 
generales sobre el tema, sino que más bien apunta a comprender un problema social que releva la perspectiva de individuos, los saberes que acusan sobre sus interacciones con otros y las prácticas de sentido que hacen emergente en el relato de su propia vivencia migratoria.

\section{Metodología}

El enfoque metodológico de la investigación es de carácter cualitativo con diseño de tipo fenomenológico, y construye el objeto de estudio a partir de una aproximación a la experiencia migratoria de los participantes con la finalidad de comprender e interpretar el conocimiento que poseen sobre el migrar y ser migrante a través del análisis de sus propios relatos. Para ello se utilizó el método de la Teoría Fundamentada y sus procedimientos de codificación abierta, axial y selectiva (Strauss y Corbin, 2002; Glaser y Strauss, 1967; Salinas, 2009; Flores y Naranjo, 2013), como guía orientadora para la producción de resultados descriptivos, relacionales e interpretativos. La técnica de recolección empleada fue la entrevista semiestructurada con guion temático, y estableció temas generales articulados en torno a tres «momentos» clave: 1) El de salida, que exploró las motivaciones individuales y los factores de atracción/expulsión externos que configuraron la acción de emigrar; 2) el de asentamiento, centrado en comprender los procesos de asimilación e integración a los nuevos contextos socioculturales y los procesos de transformación de identidad en torno a la residencia actual; 3) el de retorno, como ejercicio de imaginación y discusión sobre su posibilidad.

Se llevaron a cabo dos tipos de muestreo. En una primera etapa, uno de carácter emergente aplicado como muestreo en red, en que se identificó y contactó a los primeros participantes que posibilitaron el acceso a los siguientes, determinado por criterios de inclusión y exclusión como sigue. a) De inclusión: I) migrantes extranjeros provenientes de cualquier nacionalidad, II) con estancia en el país no superior a cinco años, III) con residencia en las ciudades de Valdivia, Osorno, Puerto Montt y Castro, IV) mayores de edad; b) De exclusión: I) Turistas, diplomáticos, negociantes de corta estancia, estudiantes, refugiados o asilados y descendientes de migrantes nacidos en Chile, II) Personas que padezcan trastornos en sus facultades mentales. En una segunda etapa, predominante, se aplicó una estrategia de muestreo teórico en que la selección respondió a la necesidad de buscar perfiles heterogéneos que permitieran abrir temáticas nuevas o profundizar y discutir aquellas consideradas relevantes a partir del análisis de los primeros relatos, situación que condujo a modificar la pauta de entrevistas durante el transcurso de la investigación. Así, la selección de participantes se configuró por la factibilidad de acceso a migrantes extranjeros de primera generación y la flexibilización de los criterios de inclusión iniciales, con lo que se amplió el período de residencia para incorporar actores con más tiempo de permanencia en el país. Con todo, el número final de participantes en el estudio fue de 21, se entrevistaron entre los meses de abril y noviembre de 2014, y se caracterizaron por estar en situación regular de documentación, 
ocupados laboralmente y poseer, en su mayoría, formación profesional previa al asentamiento en Chile (19 de 21), con algunas generalidades que se presentan a continuación.

Figura 1. Tabla de caracterización de los participantes del estudio.

\begin{tabular}{|c|c|c|c|c|c|c|c|c|c|c|c|}
\hline & \multirow[t]{2}{*}{ Subtotal } & \multicolumn{4}{|c|}{ Ciudad asentamiento } & \multicolumn{3}{|c|}{ Procedencia } & \multicolumn{3}{|c|}{ Rango Edad } \\
\hline & & Valdivia & Osorno & $\begin{array}{l}\text { Puerto } \\
\text { Montt }\end{array}$ & Castro & $\begin{array}{l}\text { Latinoamericana } \\
\text { y Caribeña* }\end{array}$ & Europea** $^{\star \star}$ & $\begin{array}{l}\text { Asia y Oriente } \\
\text { Próximo*** }\end{array}$ & $24-35$ & $36-47$ & $\begin{array}{l}48 \text { y } \\
\text { más }\end{array}$ \\
\hline Mujeres & 12 & 5 & 2 & 1 & 4 & 8 & 3 & 1 & 6 & 3 & 2 \\
\hline Hombres & 9 & 4 & 1 & 1 & 3 & 3 & 5 & 1 & 6 & 3 & 1 \\
\hline Total & 21 & & & & & & & & & & \\
\hline
\end{tabular}

* Colombia, Perú, Bolivia, Ecuador, México, Cuba y Guatemala

** Bélgica, Inglaterra, Francia, Italia y Grecia

*** Japón y Egipto

Fuente: elaboración propia.

El análisis, en coherencia con las orientaciones procedimentales de la Teoría Fundamentada (Strauss y Corbin, 2002; Glaser y Strauss, 1967; Salinas, 2009; Méndez y Cárdenas, 2012; Flores y Naranjo, 2013), se desarrolló con el método de comparación constante en torno a los procedimientos de codificación abierta, axial y selectiva, apoyado en la elaboración sistemática de memos y anotaciones teóricas y operacionales que potenciaron el carácter emergente y cíclico del diseño (Coffey y Atkinson, 2003), y complementado con la estrategia de triangulación de investigadores (Denzin, 2012), que aportó criterios de fiabilidad y validez mínimos para la construcción de teoría (Hernández et al., 2006). De este modo y con uso del software Atlas.ti, se realizaron codificaciones simultáneas entre tres investigadores de disciplinas diferentes hasta lograr un acuerdo intersubjetivo respecto a la saturación y la delimitación de la categoría central. Sobre los aspectos éticos, previo a la realización de las entrevistas, se socializó con cada participante el carácter académico de la investigación, sus especificidades técnicas y el afán de publicabilidad de los resultados, dando paso a la firma de un consentimiento informado.

\section{Resultados}

El artículo presenta resultados descriptivos, relacionales e interpretativos de cuatro familias de códigos organizadas en torno a nociones que los participantes del estudio manifestaron tener sobre migrar y ser migrante a propósito de su propia experiencia migratoria. Estos resultados son producto de procedimientos de comparación sistemática de categorías conceptuales y se dividen en dos partes: la primera objetiva los procesos de transformación identitaria y la experiencia de aprendizaje y desarrollo personal de los migrantes en el asentamiento; y la segunda desarrolla tres modelos explicativos que relacionan las categorías buen migrante, inmigrante y migrante como persona común y corriente. 
Todo se acompaña con extractos de entrevistas de los participantes, pues aquel es el sustento de la metodología utilizada en el estudio, y la etiqueta de identificación para cada texto citado es, entre paréntesis y en este orden, el siguiente: consonante mayúscula que indica sexo ( $\mathrm{H}$ para hombre y $\mathrm{M}$ para mujer); edad explícita con números; pais de origen, indicado con las tres primeras iniciales, y finalmente ciudad de asentamiento, repitiendo la misma operación. Con ello y a modo de ejemplo, la abreviatura (M38ITAVAL) se lee del siguiente modo: «Mujer de 38 años de nacionalidad italiana y asentada en la ciudad Valdivia».

\subsection{Nociones asociadas al migrar}

a) Migrar como proceso de transformación identitaria:

Vehicula los tránsitos cognitivos, afectivos y relacionales que el migrante construye para enfrentarse a la sociedad de llegada en torno a cuatro procesos asociados:

I) De aculturación: entendido como aquel en que el migrante modifica, voluntaria y/o involuntariamente, pautas de comportamiento propias de sus arraigos culturales de origen para adoptar las del lugar de asentamiento, tanto por motivos instrumentales que implican cometer acciones bajo pretensión de ser aceptado en la sociedad de llegada para cumplir los objetivos de emigración, como por afinidad y comodidad, que deviene en identificación con las prácticas culturales del lugar de llegada:

El peruano toma cerveza de un solo vaso... todos tomamos del mismo vaso. Acá cada uno tiene su vaso y es más higiénico. $\mathrm{O}$ sea, hay cosas que uno rescata y tiene que aprender. Allá hago el esfuerzo con mi familia y amistades cercanas porque la cultura es así. Pero acá, entrar a este grupo [peruanos] que mantiene ese aspecto, hacer eso otra vez con gente con la que no voy a comunicarme no creo que valga la pena. (H43PERCAS)

Allá la mala costumbre que tenemos los peruanos es orinar en la calle. Entonces, si un peruano viene a Chile y se pone a orinar, a tomar o a comer en la calle, ¡qué pasa! Allá sí, allá la gente camina con su comida en la mano y es algo natural. Hasta la gente cuica [con dinero] compra su comida y se va caminando por la calle. Acá no es así. Hay ciertas prácticas que uno va adquiriendo acá y sabe que son buenas y las mantiene. (H43PERCAS)

II) De diferenciación cultural: en que la calidad de foráneo persiste a pesar de que el migrante se haya adaptado al nuevo repertorio sociocultural de la ciudad y país de asentamiento, cuya experimentación ocurre tanto a nivel subjetivo como objetivo, derivado principalmente de cómo les afectan los discursos públicos y privados que los nativos producen sobre ellos (con apelaciones físicas o idiomáticas como "gringo" para el caso de los europeos o "cholo" para el de los peruanos). Esto se hace patente aun sin importar los niveles de integración funcional alcanzados en la comunidad de asentamiento como refiere una 
participante francesa: «Y acá siempre, aunque uno se integra y todo, siempre hay un momento en que te hacen sentir que no eres de acá». (M27FRAVAL)

Sin embargo, hay otros modos de relaciones inmediatas que convierten esta incorporación subordinada homogénea (de extraño frente al nativo) en un código social heterogéneo que establece pertenencias como diferencia también entre migrantes. Así, por un lado, emergen identificaciones regionales en las que los actores se reconocen o congregan como latinos, europeos o no latinoamericanos, reivindicando atributos singulares que los distinguen y jerarquizan, como ejemplifica una participante colombiana y otra de origen japonés.

Nosotros los latinos como personas tenemos un cariño y un sentido de propiedad y de lucha y de sigamos metiéndole empeño a la cosa, que ellos [los europeos] no tienen... ellos ya lo tienen todo. (M33COLCAS)

...Gente europea o de Estados Unidos, yo me entiendo todo muy bien, pero latinos en realidad no, no, es un poco difícil, o me voy a estresar. (M29JAPVAL)

Por otro lado, un migrante de procedencia francesa frente a un hablante chileno constituye su pertenencia social y cultural como francés; frente a un peruano como un europeo; y frente a un coterráneo como un nosotros, a lo que se suman múltiples posiciones de habla y sentidos de autoridad.

III) De integración: primero, concebido como un esfuerzo de traducción cultural que los migrantes basan en la reflexividad de las interacciones de la vida cotidiana con el propósito de integrarse a la sociedad de llegada; y luego, como modo de concebir el lugar de asentamiento como una "nueva casa» o «un segundo hogar», cuya identificación releva aspectos culturales y afectivos, enunciados en expresiones como «me siento parte de ellos». Del mismo modo, se encuentran aquellas pertenencias culturales mixtas que, a través de expresiones como "me siento chilombiana» o "me siento chilonteco", destacan la identificación con y la incorporación de prácticas culturales del lugar de asentamiento, su gente y su vida cotidiana en general, pero manteniendo siempre rasgos, prácticas y por encima de todo un sentimiento de orgullo e identificación con el país de origen.

IV) Resistencia a la pérdida de elementos culturales de origen: corresponde a lo que algunos migrantes denominan «mantener raíces» $\mathrm{o}$ «mantener la substancia», y se refleja en la reproducción que para sí y con el entorno inmediato hacen de conocimiento y prácticas de procedencia, consumiendo y disfrutando bienes simbólicos propios de la industria cultural (como música o cine documental) y también otros quehaceres de origen (como la comida, la relación con la naturaleza o el uso de la lengua oral y escrita) cuya perpetuación ocurre a través de su socialización con los hijos:

La substancia que circula acá en mi casa es todavía de Italia. La comida, los libros y la música son las primeras cosas que se me ocurren; el resto, las cartulinas del Coliseo, el Piazza Fontana di Roma.... (M38ITAVAL) 
Cuando chicos, lo primero fue la música, un año y tú le cantas, entonces lo que me sale son canciones italianas, no canciones chilenas o inglesas. Los libros, los personajes típicos de los libros italianos con que uno creció. Y después las películas o los videos, (M38ITAVAL)

Nosotros en Bolivia sembramos quinoa, habas, papa, ajo, cebolla, todo se siembra... Se siembra zanahoria, lechugas, todo. Entonces, mis papás nos criaron en eso y yo no puedo cambiarlo. Sigo así. Yo enseño a mis hijos y ellos me dicen: ¡No, mamá, no trabajes, hay que comprar la papa!. (M50BOLOSO)

\section{b) Migrar como proceso de aprendizaje y desarrollo personal:}

Otra de las formas de concebir la migración por parte de los migrantes releva una dimensión emocional y espiritual. Aquí, de modo transversal en todos los participantes del estudio, la migración es vista como posibilidad de crecimiento y desarrollo personal, en que los individuos se abren al descubrimiento de otras culturas, se aventuran a la realización de sus sueños y se enriquecen como seres humanos, asimilando el proceso migratorio con el desarrollo de cualidades como la tolerancia y la voluntad de aprender a «querer al otro viviendo con la gente», es decir, como una experiencia de aprendizaje cognitivo en sentido amplio y no dogmático, tanto emotiva como intelectual, pero también es material y a veces se relaciona con lo religioso. Respecto al enriquecimiento como ser humano, un participante peruano y otro de origen belga, señalan:

Migrar es enriquecerse como ser humano, [...] sea por un tema laboral, conocer nuevas culturas, quedarse un tiempo o hacer un intercambio. Creo que lo mejor para una persona es ir a otro país, definitivamente. En mi experiencia es lo mejor. (H43PERCAS)

Enriquecerme con otra cultura y aprender a querer a la gente. Si me hubiese quedado en Perú no hubiese aprendido a querer a la gente chilena, o sea, aprendí a quererlos viviendo con ellos, compartiendo sus alegrías, sus penas [...] cosa que no pensé cuando salí del Perú. (H43PERCAS)

También es la posibilidad de descubrir otra cultura, otra manera de vivir, otro mundo. Es muy interesante. Permite crecer como hombre, como gente, ser mejor por conocer más maneras de vivir. (H28BELVAL)

Paralelamente, la migración internacional es vista como un desafío en que los migrantes se enfrentan a sí mismos, probándose frente a lo nuevo y asumiendo la resiliencia como elemento fundamental para no ver el asentamiento como un fracaso ni el retorno como escape a todo lo que resulte adverso. Con ello, lo resiliente se reivindica, ante todo, como práctica de autoconocimiento que se homologa con un enfrentarse a sí mismo, como comentan un migrante guatemalteco y otro egipcio:

También es resiliencia, porque es fácil irse: allá tienes a tu gente, tus viejos, hermanos, amigos... Fue una posibilidad volverme a Guatemala y en algún 
momento mi viejo me dijo: 'Oye, qué estás sufriendo en Chile, vente a Guatemala'. Fue un momento de conocer ese lado oscuro. (H32GUATVAL)

Me enfrenté conmigo mismo y dije no, no me voy, quizás más adelante, pero debo pasar esta etapa. Fue por mí, no por otra cosa en el país. Me enfrenté y hablé entre mí mismo y dije no, debo pasar esto para mostrarme que sí puedo y después pensar volver. Y cuando me enfrenté con esto me pasé de dos a tres meses, y ya empezó a gustarme más la cosa; empecé a hablar más español, a comunicarme con gente, a encontrar lugares donde comer, a conocer comida que yo puedo comer. Y todo eso facilitó que yo me quede aquí. (H44EGIVAL)

Concebir el hecho de migrar como experiencia de crecimiento personal también suma una posibilidad en que los participantes se ven a sí mismos como actores que aportan calidad humana a otras personas en el plano de sus interacciones cotidianas. Esto se objetiva en quehaceres de servicio que buscan aportar a la movilidad social de personas en situación de vulnerabilidad en Chile, cuya vocación desborda explícitamente la mera funcionalidad de cumplir objetivos laborales, como ocurre con un participante peruano y otro belga, que, desenvueltos en las áreas de las capacitaciones y los proyectos sociales vinculados con la música, aportan al desarrollo técnico y emocional de quienes ingresan a sus programas, aportes que según ellos mismos muchas veces no serían percibidos por la comunidad de asentamiento.

Para otros migrantes, en cambio, esta mirada se configura como rol de "guía espiritual», cuyo propósito es vehicular el acercamiento a Dios de quienes se crucen en sus trayectorias vitales en cada una de las ciudades de asentamiento, como ocurre con una participante ecuatoriana y otro participante egipcio. En el primer caso, la actora explicita que sus razones de migración, más que económicas, estuvieron motivadas por lo que denomina "palabra proclamada», cuya enunciación orientó su voluntariedad de servicio «al prójimo» y prácticas de evangelización en una ciudad tan al sur del país como Castro. En el segundo caso, el actor egipcio indica que uno de los motivos fundamentales de su permanencia en Chile es el trabajo de orientación a sus prácticas religiosas en la Comunidad Islámica de Valdivia, pues esta es una comunidad arabodescendiente de segunda y tercera generación, y él, en cuanto nativo conocedor de la cultura musulmana y los territorios históricos que practican el islam, se consolidó como guía confiable para aprehender su conocimiento y afectividad religiosa y cultural.

Las especificidades anteriores son muy valiosas, pues dan cuenta de concepciones positivas y variadas del migrar desenvueltas en las voluntariedades cotidianas de quienes migran. Sin embargo, ahora resulta necesario destacar información que sitúa el proceso migratorio como conjunto de formas de hacer impuestas a los migrantes a través de pautas de comportamiento que configuran sus procesos de adaptación, y por tanto la incorporación de nociones instituidas del lugar de asentamiento y el desarrollo de actitudes que los actores deben tener frente a la sociedad de llegada, como se desarrolla a continuación. 


\subsection{Nociones asociadas al ser migrante}

Este ítem se divide en tres partes: primero presenta concepciones sobre ser migrante articuladas en torno a valoraciones positivas que los participantes homologan con la noción buen migrante; luego presenta concepciones negativas vinculadas con la noción inmigrante, y finalmente, como intento por desbordar la violencia clasificatoria que sobre ellos recae en su calidad de foráneos, los participantes hacen emergente la noción migrante como persona común y corriente, en cuanto reivindicación que cada uno hace sobre sí como «ser humano» igual de digno e importante que cualquier otro.

\subsubsection{Buen migrante}

En el modelo, la noción buen migrante emerge como situación contextual asociada a cómo creen los migrantes que son percibidos por los chilenos, en lo que se identifica, por una parte, elementos de un perfil deseado de migrante en Chile influenciado por lo que los participantes conciben como «baja autoestima como país»; y por otra parte, elementos de un proceso asociado al comportamiento que los migrantes «deben tener» una vez asentados en el territorio nacional. Con respecto al primero, la caracterización del perfil deseado se asocia a las clasificaciones "extranjero" y "migrante de aventura», cuyos motivos de emigración estarían relacionados con razones afectivas, de formación profesional, recreacionales y principalmente no laborales. Estos elementos, además, vehiculan explícitamente la preferencia que los chilenos tendrían por los europeos, cuya valoración positiva se articularía en base a prejuicios como que «son más adinerados», "más desarrollados» $\mathrm{O}$ «más inteligentes»:

Figura 2. Buen migrante

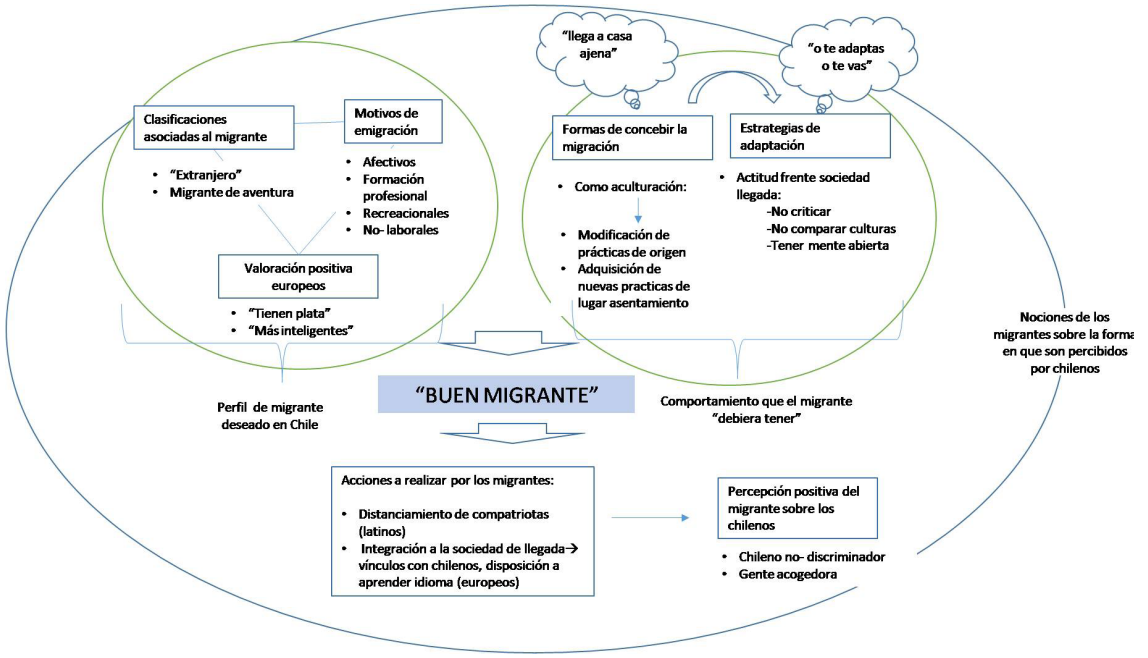

Fuente: elaboración propia. 
A los europeos se los cree como Dios, los exaltan. Por ejemplo, a mí me exaltaron: por Grecia, por la antigua Grecia... Y okey, buena aceptación. (H35GRIECAS)

Hay diferencias... y cuando ves a un italiano, un francés o un estadounidense se nota. Esa gente tiene otra clase, es más elegante y viene a dejar su dinero, no viene a robar ni a matar, viene a disfrutar. Un colombiano, un ecuatoriano o un peruano viene a lo mismo pero lastimosamente se cree que vienen a hacer daño. A los otros se les dan todas las regalías. (M36COLCAS)

$\mathrm{Al}$ momento que digo 'soy francesa' o cuando notan que tengo un acento, hay una mirada como de admiración: ‘¡Tú eres europea!'. No sé qué se imaginan de los franceses o de París, no sé, ni yo conozco París... pero te asocian a muchas cosas: el queso, el vino, perfumes, Cannes, muchas cosas que en realidad ni siquiera forman parte de mí. (M27FRANVAL)

Peruanos, como chilenos, pensamos que los europeos merecen un trato diferenciado: porque son más desarrollados o porque nuestra autoestima como país no está tan encima y no creemos que podamos ser mejores que ellos. (H43PERCAS)

Por otro lado, los participantes consideran que deben tener ciertos comportamientos «esperados» en el lugar de asentamiento, pues construyen percepciones culturales que los someten a la sociedad de llegada basadas en nociones como "o te adaptas o te vas» o el migrante «llega a casa ajena». Esta cristalización heterónoma repercute en una forma de concebir la migración como un proceso de aculturación, que en muchos casos implica la modificación de prácticas de origen y la adquisición de otras propias del lugar de asentamiento.

Tienes que adaptarte a las personas y ser empático, debes tener claro que estás llegando a casa ajena, entonces tú tienes que acostumbrarte a la cultura, la cultura no se va a acostumbrar a ti. Cuando llegas a un lugar bajo ese pensamiento, es más fácil que te puedas adaptar, o sea, habían cosas que conmigo no cuadraban, pero uno las reflexiona. (H43PERCAS)

La inmigración hay que vivirla con paciencia y nunca perder la realidad, que sencillamente es que uno no es del país. De repente las cosas no funcionan como uno quiere y hay que aceptar eso, no hay que chocar. Me he encontrado muchos extranjeros que chocan y no paran de quejarse: ‘QQue cómo el país o esta persona es así y bla, bla, bla...!’. ¿No te gusta? Así es. Entonces, o lo aceptas o te vas. (H35BELVAL)

Lo anterior implica, directamente, el desarrollo de estrategias de adaptación relacionadas con la actitud que debe adoptar el migrante frente a la sociedad de llegada, entre las cuales no criticar, no comparar culturas y tener la mente abierta forman parte de condiciones indispensables para lograr tal adaptación. Estos elementos configuran procesos que hacen emergente la noción buen migrante 
en cuanto valoración positiva que va ubicando al otro extranjero como actor integrado a la sociedad de llegada previa exigencia de ciertas acciones, como el distanciamiento de connacionales y la proyección de mayor vinculación con chilenos - como ocurre con participantes de origen latinoamericanoo el aprendizaje de la lengua local para hablarla en grado básico, como relevan migrantes de origen europeo, asiático y árabe:

Sé que me sentiría a gusto con mis compatriotas, pero involucrarse mucho es mantener las costumbres y hay cosas que nosotros queremos cambiar. $\mathrm{O}$ sea, hay cosas que me gustan del pueblo chileno, entonces trato de no mezclarme con peruanos. O sea, si me junto con ellos me van a empezar a invitar y quizá no es lo que queremos; este espacio lo queremos aprovechar al máximo. (H43PERCAS)

El despliegue de las acciones anteriores, y sobre todo la mayor vinculación con los actores locales, impacta a su vez en la percepción positiva que los migrantes tienen sobre los integrantes de la sociedad de llegada, destacando cualidades que se expresan a través de nociones como «chileno no discriminador» o "gente acogedora». Con todo, buen migrante emerge, en el marco de nuestro análisis, como una construcción racional que articula una red de relaciones interdependientes determinadas por un imperativo funcional, que es vivir en el lugar de asentamiento de un modo que permita cumplir objetivos habitando espacios materiales y simbólicos de confort, y donde la reflexividad que cada actor hace sobre su quehacer cotidiano es un elemento clave para la construcción de ese tipo particular de proceso migratorio.

\subsubsection{Inmigrante}

En el modelo, la noción inmigrante emerge como signo lingüístico que representa percepciones negativas sobre la figura del migrante dentro de un contexto general asociado a la calificación que los participantes del estudio hacen de las políticas nacionales de migración como «estrechas». Según los actores, esta calificación se objetiva en base a las exigencias legales que impone el país para la residencia de extranjeros, relacionadas con poseer un contrato laboral previamente pactado para solicitar una visa de trabajo; contar con la figura de un aval financiero para los casos de migrantes que no puedan acreditar solvencia económica; o estar matriculado en un programa de estudios académicos para acceder a la visa de estudiante, entre otras. Tales exigencias, sumadas a una excesiva burocracia para su tramitación, terminan instalando, además, la idea de que la entrada de los migrantes a Chile es selectiva en base a su nacionalidad y aquello discriminaría negativamente a los de origen latinoamericano:

Por temas de narcotráfico y orden público, los colombianos siempre estamos ligados a esa mala fama y es muy terrible... En todas partes tenemos muchos problemas justamente por esto..., para poder viajar, obtener visa, para los trámites migratorios. Es muy complicado y siempre hay una fila de colombianos aparte de la fila del resto del mundo. (M35COLVAL) 
Figura 3. Inmigrante

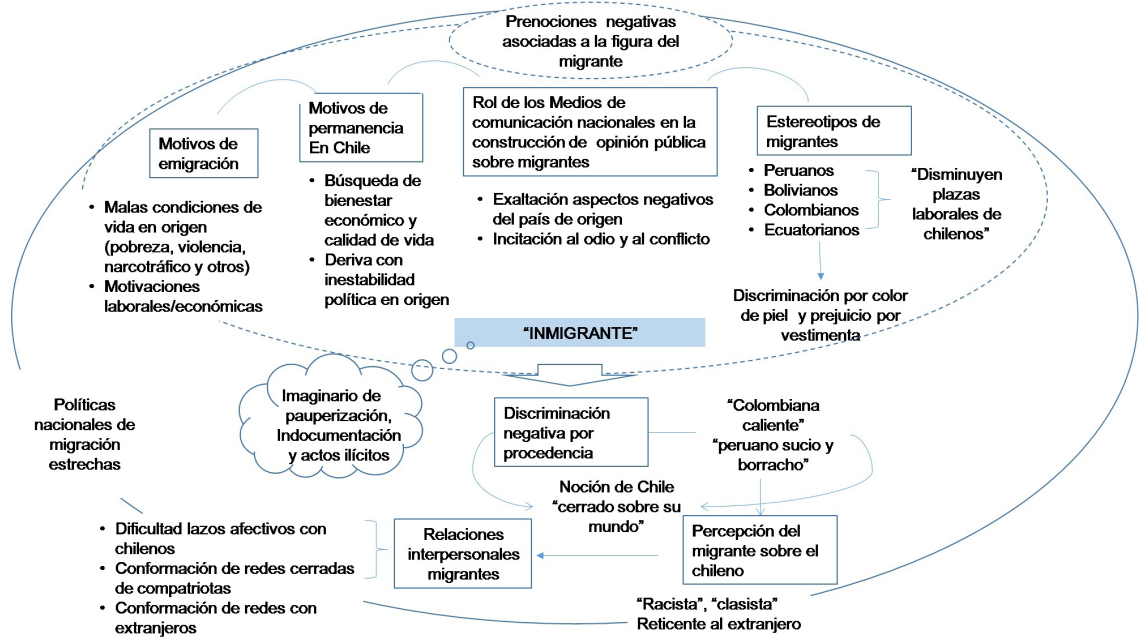

Fuente: elaboración propia.

Sin embargo, es necesario acotar que esta percepción de las políticas migratorias nacionales se releva de modo más enfático entre participantes del viejo continente, producto, fundamentalmente, de la diferencia que establecen con la facilidad de circulación que existe entre los países miembros de la Unión Europea, como señala un actor inglés:

Aquí en Chile tienen una cosa extraña con esto de los inmigrantes. Siempre ser inmigrante es difícil, porque hay un montón de cosas que por ejemplo no noto en la Unión Europea... Allá puedes pasar de un país a otro sin gran dificultad, puedes trabajar en otro país sin gran dificultad, no hay que hacer un montón de papeleos como acá. (H24INGCAS)

Dentro de estos elementos generales de contexto, se articulan otros inmediatos que hacen emergente la noción inmigrante como sentido negativo, según los participantes potenciados por un «excesivo y peligroso nacionalismo chileno", que serían los siguientes: a) Motivos de emigración, entre los que destacan las «malas condiciones de vida en origen» y las «motivaciones laborales y económicas»; b) motivos de permanencia en Chile, asociados sobre todo a la inestabilidad política y económica en origen y nuevamente a motivos laborales (como ocurre en casos de participantes de origen europeo y de Oriente Próximo); c) el rol de los medios de comunicación, que fabricarían la mala percepción que los chilenos tienen sobre los migrantes exaltando aspectos negativos, incitando al odio y "perpetuando" conflictos nacionales entre países fronterizos; d) la existencia de estereotipos negativos instalados en el país sobre migrantes de nacionalidad peruana, boliviana, colombiana y ecuatoriana, asociados a la idea 
general de que vienen a disminuir las plazas laborales de los chilenos. Algunas evidencias las entregan relatos de participantes de origen egipcio, guatemalteco y francés:

La prensa siempre relaciona el terrorismo con los musulmanes. Si hay alguna bomba o si hay terrorista, es musulmán, sin saber si es verdad o no. Es una imagen que, perdóname, es una imagen falsa. Entonces la gente ya no tiene en cuenta cómo es la imagen verdadera y no nos conoce. (H44EGIPVAL)

Por ejemplo, los peruanos son los que vienen a trabajar barato y los bolivianos son las nanas bolivianas [trabajadoras domésticas de bajo prestigio social y económico]... Hay cosas así, es como los gringos y los latinos. Pero yo, personalmente, no tengo esa percepción, no creo que sea así, pero me da la sensación de que la gente lo percibe de esa manera. (M27FRAVAL)

En situaciones en la calle, después de salir de algún carrete [juerga] me iba caminando a la casa y me pedían un cigarro. '¿Y de dónde sos?'. 'De Guatemala'. 'Hijo de puta... vete, extranjero... Deja de robarnos el trabajo, lárgate!'. Siempre este tipo de cuestiones. Como que a veces tienen ese nacionalismo que a mí me parece una estupidez. (H35GUAVAL)

Todos estos elementos confluyen en la construcción de la noción inmigrante como categoría social que remite a imaginarios de pobreza, desorden, indocumentación, peligrosidad y delincuencia. Con aquello, la significación impacta en la vida cotidiana de los migrantes como discriminación negativa en función de su procedencia, color de piel y apariencia física, situación que en los participantes instala la idea de "Chile cerrado sobre su mundo" y potencia su percepción de los chilenos como «racistas, clasistas y reticentes al extranjero»:

Dependiendo de donde vengas te tratan. O sea, ustedes, de tan cerrada la mente, piensan que los peruanos son así y son asá, y hay de todo en esta vida, gente buena y gente mala. (H35GUAVAL)

En el colegio en que entró mi hija los profesores ningún problema, pero de otros compañeritos, no todos pero sí algunos, hubo burlas. Le decían que se pintaba de negro, que se ponía betún en la cara, que era india, que tenía bigotes, que era fea, esas cosas que en ocasiones causaban cierto malestar. (M33COLCAS)

En Chile ven mal a la gente más oscurita de piel, a los sudamericanos... De Ecuador, Perú o Colombia no somos tan bien recibidos. (M37COLOSO)

El último punto afecta negativamente a migrantes latinoamericanos, pero existen otros elementos de exclusión cultural que afectan todavía más en casos particulares de mujeres colombianas asentadas en la ciudad de Castro, producto de un estereotipo que las cosifica sexualmente y trunca su posibilidad para construir lazos afectivos con chilenos, lo que las obliga a articular redes 
cerradas entre connacionales. Y esto ocurriría por dos aspectos: uno, las barreras que a esa implicación afectiva imponen las mujeres locales por considerar a las migrantes como amenaza para sus relaciones amorosas («vienen a quitarnos el marido»); y otro, que las mismas migrantes reprimen su kinésica y expresión emotiva, con ejemplo de sus formas de bailar y reír en público, que a ojos de los integrantes de la comunidad receptora serían manifestaciones de escándalo e insinuación sexual relacionada directamente con la prostitución:

Muchas mujeres de otros países vienen al trabajo de la prostitución. Entonces acá las mujeres piensan que uno viene a lo mismo. Pero no todas son así, no todas venimos a prostituirnos. (M36COLCAS)

He tratado de vivir tranquila y siento que tengo una buena forma de actuar, pero llevo seis años y no puedo decir que tenga una amiga con quien contar. No, en eso no he podido hacer buenos lazos. Pero no va por mí. Para las chilenas, nosotras somos expertas en tener sexo y queremos acostarnos con todo el mundo, entonces, con mis compañeras de trabajo mejor tratamos de lejitos, somos cordiales pero hasta allí nomás, para evitar cosas. (M33COLCAS)

Estas clasificaciones afectan directamente todas las interacciones de la vida cotidiana de las participantes y, de acuerdo a sus propios relatos, serían producto de un arraigo cultural machista, manifiesto como conjunto de significaciones imaginarias sociales (Castoriadis, 2002) asociadas al recato del comportamiento que la mujer debe tener en el espacio público, que, sumado a un racismo que segrega por color de piel y un imaginario social que instituye lo colombiano como agente de pauperización en Chile, entra en pugna directa con su proxémica y gestualidad, e inaugura la noción "colombiana caliente» como expresión coloquial descalificatoria con la que los actores locales se refieren a ellas:

Una compatriota me decía que el problema es que las chilenas piensan que las colombianas venimos a quitarles el marido, a quitarles su puesto, entonces evitan abrir demasiado las puertas de sus casas [...] Y me decían 'colombiana caliente', cosas tontas pero que afectan, son incomodas. (M33COLCAS)

\subsubsection{Migrante como persona común y corriente}

El modelo explicativo identifica la noción migrante como persona común y corriente como fenómeno central emergente de dos contextos: uno, de condiciones intervinientes generales de digitalización global de las comunicaciones; y otro, de condiciones contextuales mediatas de migración internacional en Chile.

Sobre los elementos del contexto estructural, la digitalización de las comunicaciones se refiere a un proceso de globalización en que se produce una informatización general de la sociedad, que determina que la producción de la vida cotidiana, en sus dimensiones públicas y privadas, pasa a ser mediada por las nuevas tecnologías de la información y las comunicaciones, como modelo hegemónico que socializa la producción y el consumo cultural (Ianni,1998). 
Figura 4. Migrante como persona común y corriente

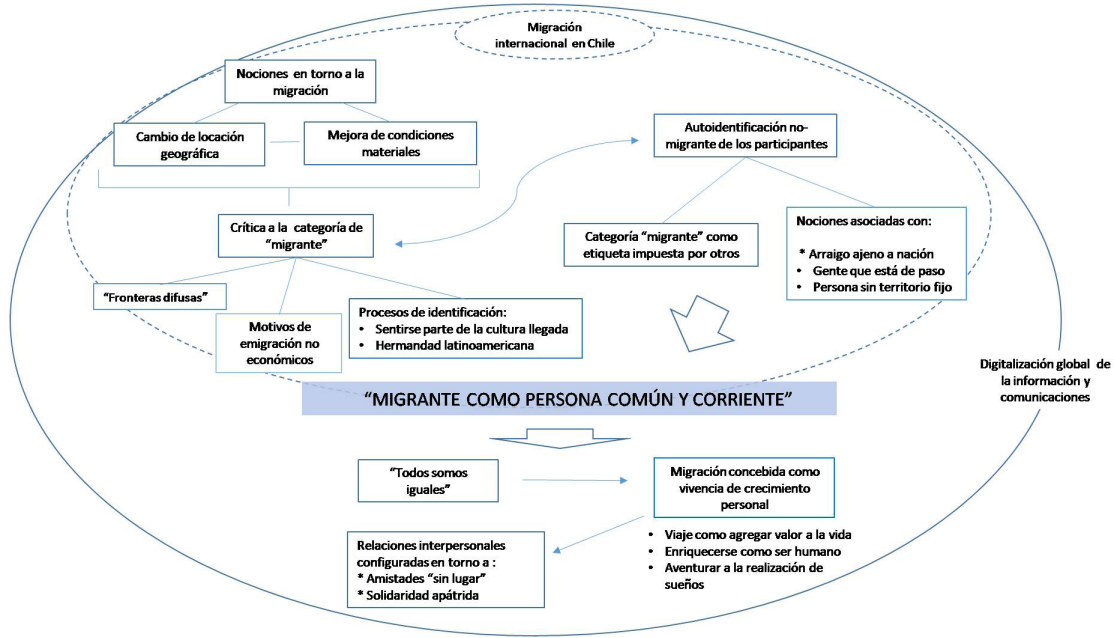

Fuente: elaboración propia.

En este plano, la circulación global de información y conocimiento a través de internet, y el uso de redes sociales, funciona como medio a través del cual se configuran relaciones de intercambio intangibles en general, que posibilitan la conformación de lazos afectivos entre personas de locaciones geográficas distantes (Appadurai, 2007), y que emerge por tanto como factor clave en la toma de decisiones vinculadas a la emigración de algunos de los participantes de nuestro estudio. Complementariamente, estos procesos enmarcan elementos de contexto mediato asociados con dinámicas actuales de migración internacional en el país, y nociones instituidas en torno a la migración y al ser migrante que entienden el fenómeno solo como un proceso de cambio de locación geográfica en pos de una mejora de las condiciones materiales (con lo que se reduce a los migrantes a meros sujetos ajenos al país que llegan motivados solo por razones económicas).

Sobre lo anterior, los participantes del estudio erigen una crítica en torno a tres aspectos: a) uno asociado a la noción de «fronteras difusas», en que la calidad de migrante ya no se clasifica en torno a limitaciones físicas rígidas, tales como país de procedencia, sino que tendría un carácter simbólico flexible asociado a identificaciones de distinto tipo como de género o políticas, entre otras; b) otro relacionado con motivos de emigración no laborales en que identifican motivaciones afectivas, inquietudes por descubrir nuevas culturas, búsqueda de privacidad o anhelos de mayor contacto con la naturaleza; c) uno final vinculado con procesos de identificación simbólica como sentirse parte de la cultura local o relevar un sentido latinoamericanista, para el caso de algunos participantes de la región.

Tales aspectos conllevan a que los participantes no se identifiquen con la clasificación instituida "migrante» por dos motivos: primero, por concebir la noción como una mera «etiqueta» impuesta por terceros que no haría más 
que levantar barreras entre las personas provenientes de otros países y los nativos del lugar de asentamiento; y luego, por asociar la noción con las ideas «arraigo ajeno a nación», "persona sin territorio fijo» y «gente que está de paso».

Como una persona sin territorio fijo, me siento cada vez más así, sé que puedo estar aquí como podría estar en x o y lugar. El migrante tiene la sabiduría y el conocimiento para poder empezar en un territorio distinto cada vez y sabe que las raíces más bien están en uno que en una nación o un país. (M35COLVAL)

Los elementos mencionados hacen emerger la noción migrante como persona común y corriente como pretensión de subvertir todas aquellas etiquetas que los asocian a concepciones canónicas, por un lado, y como desborde de las distinciones concebidas como barrera para su relación con los demás, por otro. Esta noción, a su vez, seguiría modificando la comprensión y actuación colectiva de los actores en el mundo, pues si hubo un elemento común en la totalidad de los participantes frente a la pregunta ¿qué entiende por ser migrante?, este fue la categórica afirmación «todos somos iguales». Con ello, se entrevé la poca relevancia que los participantes conceden al lugar de procedencia y queda manifiesta su comprensión del proceso migratorio principalmente como vivencia de crecimiento personal, relevando, entre otros elementos, el valor afectivo del «viaje» y el contacto con otras culturas como enriquecimiento humano y como forma de aventurar la realización de sus sueños.

Hay algo bastante importante en cuanto a viajar... Henry Miller decía que viajar es la única cosa que compras y que realmente tiene valor. Una persona que está viajando está agregando valor a su vida. (H25INGCAS)

De igual modo, esta aproximación a la experiencia migratoria como intento de construcción subjetiva impacta más críticamente las relaciones interpersonales de algunos participantes que vehiculan, explícitamente, sus relaciones afectivas en torno a ideas como "amistades sin lugar» $\mathrm{y}$ «solidaridad apátrida», que emergen como relevo de prácticas de cooperación mutua entre personas que atraviesan procesos similares.

En un momento ya no eres más el colombiano o el guatemalteco, sino que todos compartimos un mismo lugar, donde sea, y tratamos de echarnos la mano. (H35GUAVAL)

Obviamente hay diferencias de fronteras y de todo tipo de cosas, pero cuando uno se acerca a la gente ve todas las cosas comunes. [...] O sea, entendiendo lo que significa no logro encasillarme en ese concepto de migrante. (M37COLVAL)

\section{Discusión}

Este artículo comprende, como fenómeno central, el proceso migratorio como conjunto de relaciones simbólicas, materiales, políticas y culturales desprovistas 
de cualquier sobrecódigo unificante, donde migrar es todo aquello que implica ser migrante, y esto último, una experiencia que construye su sentido desde la singularidad de cada individuo que la protagoniza migrando.

Tales afirmaciones emergen de un riguroso proceso inductivo propio de la metodología utilizada y están apoyadas en evidencia proporcionada por los mismos actores. Sin embargo, hay que aclarar que el propósito de esta sociología experiencial o fenomenológica no es sistematizar relatos para la construcción de un anecdotario, sino más bien disponer de su uso como guía orientadora para comprender cómo interactúan en la vida cotidiana los individuos que los enuncian, medida en la que conviene proponer algunas consideraciones generales: a) las experiencias migratorias de los participantes de este estudio son disímiles y están motivadas, en el plano personal y social, por dimensiones que van desde las emociones románticas hasta las urgencias financieras o epicúreas, pasando por discusiones morales y valoraciones existenciales singulares que exceden siempre lo netamente económico; b) tales experiencias son reconocidas como trayectorias vitales individuales que desbordan un sentido de pertenencia grupal identificado con lo migrante; c) la nacionalidad y el lugar de procedencia, sumados al aspecto físico y al desempeño laboral, inauguran relaciones de inclusión/exclusión racista entre el «ellos» migrante y el «nosotros» local, que además varían positiva o negativamente en función del género y la ciudad de asentamiento de cada uno de los actores.

Los elementos anteriores imposibilitan aprehender los principales rasgos de lo migratorio como saber homogéneo adscrito a una posición social o una práctica estandarizada producto de una racionalización general. Por el contrario, reclaman mayor atención al individuo invitándonos a preguntar sobre su singularidad e interdependencia con los fenómenos sociales en los que habita, sentido en el que es oportuno discutir tres aspectos clave en base al conocimiento construido:

1) La acción social migratoria entendida como rol en que los participantes del estudio se presentan a sí mismos y dan cuenta de sus quehaceres ante los demás (Goffman, 2009a y 2009b), en dos posiciones: I) una minoritaria en la que no son sino el rol que desempeñan, como el de guía espiritual en el caso de una participante ecuatoriana autodefinida primero y antes que todo como «luz en el camino de otros», a propósito de cumplir una tarea evangelizadora que deriva de una revelación sobrenatural; o el de «agente de desarrollo» en el caso de una participante japonesa que migró con motivo de aportar su conocimiento profesional al desarrollo productivo del país; II) otra mayoritaria en la que desempeñan ciertos roles explicitando distancia con su quehacer o reiterando ser mucho más que las tareas que ellos implican. Esta segunda situación remite a un elemento clave de la sociología de Erving Goffman (2009a y 2009b) que supone que los actores sociales juegan estratégicamente con la imagen que entregan de ellos mismos a los demás, y es en sumo importante pues también afecta la deriva identitaria que los participantes del estudio hacen con la noción migrante y el desborde permanente frente a la clausura 
que acusan traería consigo esta clasificación. En este sentido creemos que los migrantes, en cuanto actores sociales, juegan roles diferentes de modos muy distintos entre sí, cuya comprensión es clave para cualquier proyecto sociológico del individuo, pues, como señala Martuccelli (2014), urge un análisis que articule las interacciones individuales y las estructuras sociales para desbordar la generalización excesiva que oblitera la singularización de la experiencia y también una sociología de los retratos individuales incapaz de realizar análisis más transversales.

2) La falacia de la desaparición norte/sur global presente en la noción «todos somos iguales». Aun cuando es posible concebir el discurso «todos somos iguales» como un cuestionamiento crítico a las significaciones dominantes sobre jerarquización de personas, idiomas, lugares o nacionalidades, también es posible concebirlo como imaginario instituido que orienta la interpretación del mundo y va reproduciendo una falacia en que la interdependencia de todos los factores que constituyen la globalización haría desaparecer relaciones de desigualdad económica y exclusión cultural propias de lo que De Sousa Santos (2005) concibe como lógica norte/sur. Con aquello, referirnos a las migraciones internacionales implicaría discutir las visiones dominantes que interpretan la globalización junto a sus componentes prescriptivos y su comprensión como fenómeno lineal, monolítico e inequívoco dotado de abstracciones reductoras que la conciben como el gran triunfo de la razón, la libertad y la innovación, y en definitiva, como conjunto de mecanismos que conducen al progreso y la abundancia infinita (De Sousa Santos, 2005). En esta medida, es oportuno situar la noción "todos somos iguales» como construcción discursiva que forma parte de un contexto simbólico y material que suma el anhelo personal de algo que los actores desean, la fabricación de un rol migratorio a distancia para despojarse de la carga negativa que prejuicia la noción, y una dimensión políticoideológica estructural que abre una contradicción fundante entre quienes ven la globalización como energía imbatible del capitalismo y quienes la ven como una posibilidad para potenciar la solidaridad y la igualdad social entre los seres humanos. Porque hay que señalarlo: todos los participantes del estudio tienen las mismas posibilidades imaginativas, pero no todos gozan de las mismas posibilidades locutorias ni de adaptación, pues mientras a unos se los visibiliza como individuos libres cuya calidad de extranjero es exaltada para promover su inclusión, a otros se los construye como sujetos de una socialización que los discrimina y estigmatiza producto de prácticas racistas que cotidianamente los etiquetan como seres dependientes, subalternizados e indeseados (Tijoux y Córdova, 2015). En esta línea, conviene discutir algunas categorías sobre la inmigración presentes en el discurso oficial de la burocracia del Estado, que Pinzani (2010) clasifica en torno a tres dispositivos que harían de lo migratorio un problema fundamentalmente político y no solo científico: a) un discurso de control, que es de tipo administrativo y concibe la migración como fenómeno que hay que controlar jurídicamente para vehicular la lucha contra la inmigración clandestina (plano en que lo migratorio emerge como «mal inevitable» $\mathrm{u}$ oportunidad para resolver problemas asociados a bajas tasas de natalidad, entre 
otros $)^{1}$; b) un discurso de adaptación, que es de tipo normativo y valóricoconductual, e institucionaliza la idea de que los migrantes deban adaptarse a los valores o al modo de vida de la sociedad de acogida y aquellos que no lo hagan sean devueltos al país de origen, coaccionando la renuncia total o parcial de sus arraigos culturales característicos para adoptar los del país receptor (discurso reiterado en los participantes del estudio constatable en expresiones como «te adaptas o te vas» o «llegas a casa ajena», que además encuentra relación con una de las líneas analíticas con que Márquez y Correa (2015) analizan la construcción de identidades en el «desarraigo cultural», en base a historias de vida y sobre un colectivo de migrantes peruanos asentados en Santiago de Chile); c) un discurso de rechazo a la alteridad del «otro», que, según Pinzani (2010), es minoritario en el ámbito oficial, pero sería proclamado por partidos políticos de extrema derecha e izquierda que reivindicarían la clausura inmigratoria a todo actor considerado no igual o no semejante, reclamando del mismo modo la expulsión de cualquier extranjero «diferente» que ya habite el territorio nacional. Tales elementos también permiten establecer una relación entre el discurso de los participantes y la palabra pública del Gobierno de Chile a través de la página web oficial del Departamento de Extranjería y Migración, que acusa requisitos explícitos a colectivos específicos de migrantes para la solicitud de residencia en el país: «Los extranjeros de nacionalidad colombiana, peruana y dominicana deben presentar certificado de antecedentes judiciales vigente para cualquier solicitud». ${ }^{2}$ Esta exigencia corrobora declaraciones presentes en el estudio sobre el ítem discriminación en las dimensiones de la burocracia del Estado y de la exclusión cultural en la vida cotidiana, pues tanto migrantes de Oriente Medio, Europa, Asia y Latinoamérica convergen en el mayor grado de condiciones del que son objeto estos últimos y el exacerbado proceso educativo al que deben adecuarse, comprendiendo por aquello un conjunto de prácticas de comportamiento basadas en el dispositivo leguleyo, pero también en normas no escritas impuestas como imperativos funcionales de carácter doméstico que el resto de los migrantes no siempre debe considerar (Márquez y Correa, 2015; Tijoux y Palominos, 2015). En suma, expresiones como «los europeos lo tienen todo fácil», «colombiana caliente» o «la piel oscurita no es

1. Al respecto, Agar y Rebolledo (1997) señalan que en Chile existieron políticas de atracción de migrantes apoyadas por la promulgación de la Ley de Colonización de 1845, que impulsó procesos de recepción selectiva orientados a la construcción de una nación de marcado carácter europeo, cuyos criterios de aceptación consideraban desde la apariencia física hasta los aspectos morales de los extranjeros que se deseaba entraran de forma definitiva al país. Según los autores, la política coordinó la voluntad de grupos de poder que buscaban hacer de Chile un país «más civilizado» sujeto a una concepción de desarrollo y modernidad eurocéntrica imperante, que cristalizó la colonización de la región de Valdivia, Osorno y Llanquihue, al sur de Chile, con ciudadanos de origen alemán.

2. El texto fue recuperado de la página web del Departamento de Extranjería y Migración del Ministerio del Interior y Seguridad Pública, cuya misión es «garantizar el cumplimiento de la legislación de extranjería vigente en el país» en el marco de la Política Nacional de Refugio y Migraciones, y la referencia específica se encuentra en: http://www.extranjeria. gob.cl/permisos-de-residencia-3/. 
bien recibida» articulan un proceso no consensual que convierte la idea «todos somos iguales» en un anhelo humano, que en la vida social se ve desbordado por un tipo de integración que incluye excluyendo y objetiva la noción «no da igual de donde vengas» como «un vasto e intenso campo de conflictos entre grupos sociales, Estados e intereses hegemónicos, por un lado, y grupos sociales, Estados e intereses subalternos, por otro» (De Sousa Santos, 2005: 236).

3) Los imaginarios de las ciudades de asentamiento como orientación para comprender y relacionarse con el mundo: aquí prestamos atención a algunas significaciones peculiares de tres de las cuatro ciudades en las que viven y entrevistamos a los participantes del estudio, pues tienen mucho que decir sobre cómo desenvuelven su vida cotidiana. Así, Valdivia emerge como un conjunto de singularidades culturales, sociales y geográficas que remiten a nociones de ciudad joven, abierta al mundo y poseedora de "consciencia» socioambiental, donde cohabitan resabios históricos de procesos de colonización alemana de finales del siglo XIX; casi cuatrocientas comunidades indígenas mapuche localizables en los alrededores de la ciudad; migrantes internos provenientes de distintas ciudades de Chile con motivo de cursar estudios superiores; y extranjeros de diverso tipo. Derivado de lo anterior, simplemente diremos que Valdivia fue la ciudad que nos brindó mayores posibilidades de acceso a participantes, explicado, en parte, por la alta cohesión entre migrantes de diverso origen conformada en una red de relaciones, afectivas y laborales, fácilmente identificables y con características particulares: todos se encontraban bien incorporados a la comunidad local en términos laborales y/o de vida social; todos compartían una visión crítica respecto a las significaciones de su proceso migratorio; y la mayoría tenía algún vínculo con la Universidad Austral de Chile, que, por sí misma, constituye un imaginario social relevante para la configuración de la identidad valdiviana. Sin embargo, la incorporación de los migrantes en la comunidad local se manifiesta en ámbitos diferentes, cuya acción cotidiana no siempre explicita su grado de integración. Por ejemplo, para los casos de migrantes cuya integración está determinada por el trabajo, ocurren dos fenómenos interesantes. Por un lado, quienes se vinculan con la producción de conocimiento científico-tecnológico desarrollan quehaceres y rutinas productivas que posibilitan, desde lo fortuito, la conformación de relaciones interpersonales endógenas con actores de la misma área de desempeño, que al igual que los participantes son extranjeros y con quienes ni siquiera se necesita el uso de la lengua castellana, pues todos hablan inglés. $\mathrm{Si}$ a esto le sumamos que su vinculación con el entorno y con los actores locales es casi nula (sea porque no sienten la necesidad, por dificultades idiomáticas o por lo que fuere), queda la impresión inmediata de que su grado de integración es mínimo. Por otra parte, quienes se vinculan a la ciudad desempeñando labores productivas ligadas a proyectos sociales y gestión cultural protagonizan relaciones fluidas con el entorno, que incorporan interacciones instrumentales y afectivas con actores de todo tipo, tanto locales como extranjeros provenientes de contextos socioculturales diferentes entre sí, lo que, sin duda y a diferencia del caso anterior, conduce a la idea de una integración absoluta. Al respecto, 
afirmamos que pensar que los primeros no están integrados y los segundos sí carece de sentido. Por el contrario, ambos perfiles están sumamente integrados pero de acuerdo con significaciones imaginarias diferentes. Así, la vinculación endógena entre extranjeros del primer caso forma parte de una complementariedad de significaciones instituidas de la lógica magmática de la ciudad, y particularmente de la singularidad de la Universidad Austral de Chile, en cuanto agente productivo de investigación y desarrollo con visión regional y vocación de impacto global, que destaca este ámbito como uno de los fundamentales en su forma de interpretar el mundo y su modo de actuar en él. Así, aun cuando los sujetos comportan relaciones endógenas y no interactúan mayormente con actores del ámbito local ajenos a su ámbito productivo, están ahí porque son en sumo congruentes con y elaborados por la lógica identitaria de una de las significaciones instituidas más reconocibles de la ciudad; pero también están ahí, creemos, porque fueron movidos por sueños y por deseos que los invitaron a dejar otro lugar para estar en este, y eso, como entendemos desde Castoriadis (2006 y 2007), puede transgredir sin problemas el principio de contradicción. En esta misma línea, la ciudad de Osorno presenta particularidades constitutivas de su identidad en que la influencia europea, y particularmente la alemana, jugó y juega un rol fundamental para su configuración histórica y la composición de su paisaje urbano, en la especificidad de los planos arquitectónico, de consumo gastronómico y de "fauna humana», entre algunos más. También, es fundamental señalar que su identidad se erige en función del plano económico-productivo, que sitúa lo agropecuario, y específicamente la industria de la leche y la carne, como sello característico, plasmado en el eslogan La patria de la leche y tierra de la carne, que se materializa, además, en el Monumento al Toro, localizado en la Plaza de Armas. Bajo estos elementos generales de contexto, aquí presentamos dos casos de experiencias migratorias cuyo interés descansa en la peculiaridad del entramado de significaciones que protagonizan sus participantes, en cuanto actores de procedencia boliviana y francesa. Así, primero diremos que ambos desarrollan sus vidas cotidianas en el campo, pero de forma muy diferente. Una, desde la economía de subsistencia, que responde a significaciones propias de sus arraigos étnicos aymara complementados y reafirmados con los arraigos étnicos mapuche del cónyuge. Y otro, occidental, que orienta su proyecto de vida en torno a la producción artesanal de vino con miras a la producción industrial en circuitos internacionales. Dentro de la multiplicidad de diferencias que podríamos eventualmente identificar entre estos actores y sus racionalidades, al momento de pensarse migrantes ambos convergieron en la noción "todos somos iguales», problematizada anteriormente. Algo similar ocurre con algunos casos de migrantes de procedencia europea y latina asentados en Castro. Esta ciudad, capital provincial de la Isla Grande de Chiloé, presenta la particularidad histórica de constituirse como una de las tres ciudades más antiguas de Chile, ubicando a la colonización española y la herencia huilliche como parte constitutiva de su imaginario desde los orígenes. Nos parece interesante mencionar que su cualidad de isla proyecta en las experiencias de los participantes de este 
estudio una remisión asociada a una suerte de chovinismo, en que los nativos impondrían arbitrariamente clasificaciones negativas a todos los «afuerinos» o no isleños. Esto sin duda repercute en las formas en las que son acogidos los migrantes internacionales, y su procedencia, prácticas de ocio, rasgos étnicos y género cobran verdadera relevancia. Así, mientras un migrante inglés es calificado como «borracho» a objeción del hábito con que frecuenta bares para beber cerveza o tomar café, también lo es de «mujeriego", producto de una práctica cultural naturalizada que dota de autoridad a los actores locales para entrometerse en la vida privada de los demás (situación que al actor le genera hastío y lo aleja afectivamente de las personas del lugar). Por otra parte, la construcción estereotipada de los colombianos en los medios de comunicación, sumada al racismo por color de piel, el machismo e imaginarios nativos sobre el adecuado comportamiento de la mujer en el espacio público, contextualiza un proceso de adaptación muy dificultoso para migrantes colombianas "negras», con experiencias negativas que van desde el prejuicio de la prostitución y el consumo de drogas hasta la extorsión a propósito de su cosificación sexual, claramente, configurando estigmas (Goffman, 2009b) de racialización y sexualización que, en la literatura reciente publicada, Tijoux y Palominos (2015: 3) entienden como un conjunto de prácticas «en que determinados rasgos corporalizados son considerados jerárquicamente inferiores frente al 'nosotros', justificando distintas formas de violencia, desprecio, intolerancia, humillación y explotación [...] de comunidades de inmigrantes en Chile».

Todos estos elementos sirven como información contextual básica para comprender la migración internacional como conjunto de fenómenos complejos dotado de singularidades experimentadas, individual o colectivamente, por actores diversos que habitan entre coerciones situacionales e iniciativas personales (Goffman, 2009a) que la convierten en una construcción siempre inacabada (Stefoni, 2015; Márquez y Correa, 2015). La experiencia migratoria así es múltiple, difusa y no uniforme, y aparece como una invitación a preguntarnos por el individuo que la protagoniza migrando, como lo hemos intentado en este trabajo: indagando, como señala Simmel (2012), en visiones subjetivas híbridas que no son producto solo del encuentro entre las referencias significativas de origen y las instituidas en el contexto de asentamiento, sino también de un sentirse extraño dentro de un espacio afectivo y simbólico que se desea y del que no se es parte.

¿Y cuál es el principal hallazgo de esta investigación?

Descubrir que para los migrantes, primero y antes que todo, la migración es un proceso de enriquecimiento y crecimiento personal, independiente de las particularidades que motivaron su salida del lugar de procedencia y las condiciones materiales o afectivas vividas en el lugar de asentamiento.

\section{Referencias bibliográficas}

Agar, Lorenzo y Rebolledo, Antonia (1997). «La inmigración árabe en Chile: los cambios en la integración". En: El mundo árabe y América Latina. París: Ediciones UNESCO / Libertarias / Prodhufi. 
APPADURAI, Arjun (2001). La modernidad desbordada. Dimensiones culturales de la globalización. Montevideo / Buenos Aires: Ediciones TRILCE / Fondo de Cultura Económica.

- (2007). El rechazo de las minorías. Ensayo sobre la geografía de la furia. Barcelona: Tusquets.

ArizPE, Lourdes (1978). Migración, etnicismo y cambio económico. México DF: Ediciones El Colegio de México.

Augé, Marc (2007). Por una antropología de la movilidad. Barcelona: Gedisa.

BENHABIB, Seyla (2009). Los derechos de los otros: Extranjeros, residentes y ciudadanos. Barcelona: Gedisa.

BENÍTEZ, Lucía (2013). La recepción transnacional de la televisión en los proyectos migratorios. Un estudio de campo en poblaciones marroquies. Sevilla: RTVA.

BORJAS, George (2013). Immigration and the American worker. A review of the academic literature. Washington DC: Center for Immigration Studies.

Brettel, Caroline y Hollifield, James (2000). Migration theory. Talking across disciplines. Nueva York: Routledge.

CANO, María Verónica; SOFFIA, Magdalena y MARTínEZ, Jorge (2009). Conocer para legislar y hacer politica: Los desafíos de Chile ante un nuevo escenario migratorio. Santiago: División Población y Desarrollo CEPAL.

CARrère, Cristián y CARRÈre, Michelle (2015). «Inmigración femenina en Chile y mercado de trabajos sexualizados. La articulación entre racismo y sexismo a partir de la interseccionalidad». Polis. Revista Latinoamericana, 14 (42), 33-52. $<$ https://doi.org/10.4067/s0718-65682015000300003>.

CASTLES, Stephen (2010). «Comprendiendo la migración global: una perspectiva desde la transformación social». Relaciones Internacionales, 0 (14): 141-169.

CASTORIADIS, Cornelius (2006). Una sociedad a la deriva: Entrevistas y debates, $1974-$ 1997. Buenos Aires: Katz Editores.

- (2007). La institución imaginaria de la sociedad. Buenos Aires: Tusquets Editores.

COFFEY, Amanda y ATKINSON, Paul (2003). Encontrar el sentido a los datos cualitativos. Estrategias complementarias de investigación. Antioquia: Editorial Universidad de Antioquia.

Dal Lago, Alessandro (2008). Non-Persone. L'esclusione dei migranti in una società globale. Milán: Feltrinelli.

DE SOUSA SANTOS, Boaventura (1998). La globalización del derecho. Los nuevos caminos de la regulación y la emancipación. Bogotá: Instituto Latinoamericano de Servicios Legales Alternativos (ILSA).

- (2005). El milenio huérfano. Ensayos para una nueva cultura política. Madrid: Editorial Trotta.

DenzIN, Norman K. (2012). Manual de investigación cualitativa, Vol. 1: El campo de la investigación cualitativa. Barcelona: Gedisa.

DoÑA, Cristian (2002). Percepción de la inmigración reciente en Chile a través del análisis de medios de prensa. Santiago de Chile: Universidad de Chile, tesis para optar al título de Sociólogo (inédito).

Ducci, María Elena y Rojas SyMmes, Loreto (2010). «La pequeña Lima: Nueva cara y vitalidad para el centro de Santiago de Chile». EURE 36 (108), 95-121. <https://doi.org/10.4067/s0250-71612010000200005>.

Flores, Rodrigo y NARANJO, Carola (2013). «Análisis de datos cualitativos: el caso de la Grounded Theory (Teoría Fundamentada)». En: CANALES, Manuel (coord.) (2013). Escucha de la escucha. Análisis e interpretación en la investigación cualitativa, 75-113. Santiago: LOM. 
GARCÍA, José Tomás y Verdú, Ana Dolores (2008) «Imaginarios sociales sobre migración: evolución de la autoimagen del inmigrante». Revista Papers, 89, 81-101. $<$ https://doi.org/10.5565/rev/papers/v89n0.749>.

GASCÓN, Felip (2010). «Biopolítica, migraciones y pensamiento alterizado. Dispositivos mediáticos para el control de ima(r)ginarios».F@ro: Revista teórica del Departamento de Ciencias de la Comunicación, 0 (11), s/p.

Glaser, Barney y STRAuss, Anselm (1967). The Discovery of Grounded Theory. Chicago: Aldine.

GOFFMAN, Erving (2009a). La presentación de la persona en la vida cotidiana. Buenos Aires: Amorrortu Editores.

- (2009b). Estigma. La identidad deteriorada. Buenos Aires: Amorrortu Editores.

Grosfoguel, Ramón (2007). «Migrantes coloniales caribeños en los centros metropolitanos del sistema-mundo. Los casos de Estados Unidos, Francia, los Países Bajos y el reino Unido». En: Documentos CIDOB N. 13, Migraciones. Barcelona: CIDOB Ediciones.

Harvey, David (2003). Espacios de esperanza. Madrid: Akal.

Hernández, Roberto, Fernández, Carlos y BAPtista, Pilar. (2006): Metodología de la investigación. México: McGraw-Hill Interamericana.

HATTON, Timothy y WiLliamson, Jeffrey (2004). «¿Cuáles son las causas que mueven la migración mundial?». Revista Asturiana de Economía, RAE (30), 7-36.

IANNI, Octavio (1998). La sociedad global. México DF: Siglo XXI.

JiménEZ, Ricardo y HuATAY, Carolina (2005). Algo está cambiando: globalización, migración y ciudadanía en las asociaciones de peruanos en Chile. Santiago de Chile: Editorial Gotelli.

LuBE, Menara y GARCÉS, Alejandro (2014). «Estudios de caso de la migración peruana en Chile: un análisis crítico de las distorsiones de representación y representatividad en los recortes espaciales». Revista de Geografía Norte Grande, (58), 223-240. $<$ https://dx.doi.org/10.4067/S0718-34022014000200012>.

MÁRQUEZ, Francisca y CORREA, Juan José (2015). «Identidades, arraigos y soberanías. Migración peruana en Santiago de Chile». Polis, Revista Latinoamericana, 14 (42), $167-189$. $<$ https://doi.org/10.4067/s0718-65682015000300009>.

MARTÍNEZ, Jorge y OrREgO, Cristián (2016). Nuevas tendencias y dinámicas migratorias en América Latina y el Caribe. Santiago: Ediciones Naciones Unidas.

MartuCCELlI, Danilo (2014). Sociologías de la modernidad. Itinerario del siglo XX. Santiago: Ediciones LOM.

Mella, Orlando y StOHEREl, Astrid (1999). «Clima de actitudes en los inmigrantes respecto de la sociedad chilena». Revista Paraguaya de Sociología, 36 (106), 179-194.

Méndez, Leyla y CÁRDEnAS, Manuel (2012). «Hacia la construcción de un modelo comprensivo de análisis de la «situación de inmigración» de mujeres sudamericanas en Chile». Psicoperspectivas. Individuo y Sociedad, Vol. 11, N. 1, 2012, 252-272. $<$ https://doi.org/10.5027/psicoperspectivas-vol11-issue1-fulltext-192>.

Norambuena, Carmen (2004). "Chile y sus nuevos inmigrantes. Ni acogidos ni rechazados». Revista Universitaria, 85.

PEDOnE, Claudia (2010). "Cadenas y redes migratorias: propuesta metodológica para el análisis diacrónico-temporal de los procesos migratorios». EMPIRIA, Revista de Metodología de Ciencias Sociales (19), 101-132. <https://doi.org/10.5944/empiria.19.2010.2016>. 
Pedreño, Andrés (2005). «Sociedades etnofragmentadas». En: Pedreño, Andrés y HERNÁNDEZ, Manuel (compiladores). La condición inmigrante. Exploraciones e investigaciones desde la región de Murcia. Murcia: Ediciones Universidad de Murcia.

PINZANI, Alessandro (2010). «El debate sobre la inmigración como discurso ontológico político». ARBOR. Ciencia, Pensamiento y Cultura, 744: 513-530. <https://doi.org/10.3989/arbor.2010.744n1214>.

Poo, Ximena (2008). «Migrantes peruanos en la proa de la Plaza de Armas de Santiago de Chile: de umbrales a indicios de hibridez cultural». Perspectivas de la Comunicación 1(1), 8-19.

- (2009). «Imaginarios sobre migración peruana en la prensa escrita chilena: una mirada a la instalación de la agenda de la diferencia». Revista F@ro (5) 9, 1-9.

SALINAS, Paulina (2009). Procedimientos de recolección y producción de información en la investigación social. En: Salinas, P. y M. CÁrdenas. M. (eds.). Métodos de investigación social, 365-346. Quito: Ediciones Intiyan.

SASSEN, Saskia (2003). Contrageografías de la globalización. Género y ciudadanía en los circuitos transfronterizos. Madrid: Traficantes de Sueños.

- (2007). Una sociología de la globalización. Buenos Aires: Editorial Katz.

- (2013). Inmigrantes y ciudadanos. De las migraciones masivas a la Europa fortaleza. Madrid: Siglo XXI.

Simmel, George (2012). El extranjero. Madrid: Editorial Sequitur.

SOUTO GALVÁN, Beatriz (2013). Inmigración y mediación intercultural. Aspectos jurídicos. Madrid: Editorial Dykinson.

STEFONI, Carolina (2013). «Los cibercafé como lugares de prácticas trasnacionales: El caso de la maternidad a distancia». Polis (12) 35, 211-227. <https://doi.org/10.4067/s0718-65682013000200010>.

- (2015). «Reconfiguraciones identitarias a partir de habitar el espacio público. El caso de los migrantes esquineros en la ciudad de Santiago, Chile». Chungará, Revista de Antropología Chilena, 47 (4), 669-678. <https://doi.org/10.4067/s0717-73562015005000035>.

STEFONI, Carolina y FERNÁNDEZ, Rosario (2011). «Mujeres inmigrantes en el trabajo doméstico: entre el servilismo y los derechos». En: STEFoni, Carolina (2011). Mujeres inmigrantes en Chile ¿Mano de obra o trabajadoras con derechos? Santiago: Ediciones Universidad Alberto Hurtado.

STRAUSS, Anselm y CORBIN, Juliet (2002). Bases de la investigación cualitativa. Técnicas y procedimientos para desarrollar la Teoría Fundamentada. Medellín: Universidad de Antioquia.

TAPIA, Marcela y RAMOS, Romina (2013). «Mujeres migrantes fronterizas en Tarapacá a principios del siglo XXI. El cruce de las fronteras y las redes de apoyo». Polis. Revista Latinoamericana, 12 (35), 229-257. $<$ https://doi.org/10.4067/s0718-65682013000200011>.

TEZANOS, José (2007). «Nuevas tendencias migratorias y sus efectos sociales y culturales en los países de recepción. Doce tesis sobre inmigración y exclusión social». REIS (07) 117, 11-34. $<$ https://doi.org/10.2307/40184751>.

Tijoux, María Emilia (2007). «Peruanas migrantes en Santiago. Un arte cotidiano de la lucha por la vida». Polis, Revista Latinoamericana 6 (18), s/p.

- (2011). «Negando al 'otro': el constante sufrimiento de los inmigrantes peruanos en Chile». En: STEFoni, Carolina (2011). Mujeres inmigrantes en Chile. ¿Mano de obra o trabajadoras con derechos? Santiago: Ediciones Universidad Alberto Hurtado. 
Tijoux, María Emilia y Córdova, María Gabriela (2015). «Racismo en Chile: colonialismo, nacionalismo, capitalismo». Polis, Revista Latinoamericana, 14 (42), 7-13. <https://doi.org/10.4067/s0718-65682015000300001>.

Tijoux, María Emilia y PALOMINos, Simón (2015). «Aproximaciones teóricas para el estudio de procesos de racialización y sexualización en los fenómenos migratorios de Chile». Polis, Revista Latinoamericana, 14 (42), 247-275. <https://doi.org/10.4067/s0718-65682015000300012>.

WaGMAN, Daniel (2006). «Los medios de comunicación y la criminalización de los inmigrantes». En: LARIO, Manuel (2006). Medios de comunicación e inmigración. Murcia: Editorial Convivir sin Racismo.

Zunino, Hugo; EsPinozA, Lorena y VAllejos, Arturo (2016) «Los migrantes por estilo de vida como agentes de transformación en la Norpatagonia chilena». Revista de Estudios Sociales (55), 163-176. $<$ https://doi.org/10.7440/res55.2016.11>.

ZuninO, Hugo y HidALGO, Rodrigo (2010). «En busca de una utopía verde: migrantes de amenidad en la Comuna de Pucón, IX región de la Araucanía, Chile». Scripta Nova: Revista Electrónica de Geografía y Ciencias Sociales, 14 (331) s/p. 